Western North American Naturalist 69(4), ( 2009, pp. 521-536

\title{
ARTHROPOD AND PLANT COMMUNITIES AS INDICATORS OF LAND REHABILITATION EFFECTIVENESS IN A SEMIARID SHRUBSTEPPE
}

\author{
Eric T. Gardner ${ }^{1,2}$, Val J. Anderson ${ }^{1}$, and Robert L. Johnson ${ }^{1}$
}

\begin{abstract}
We describe a case study evaluating the ecological impact of Bromus tectorum L. (cheatgrass) invasion following fire disturbance and the effectiveness of revegetation as a means of rehabilitation in a degraded semiarid shrubsteppe system. The effectiveness of rehabilitation efforts was assessed relative to arthropod richness, vegetation and arthropod community composition, and ground-cover characteristics in 3 habitats: undisturbed, burned and weed infested (B. tectorum), and burned then rehabilitated with native and nonnative vegetation. Arthropods were collected in each habitat using pitfall traps. Differences in arthropod richness were compared using rarefaction curves. Nonmetric multidimensional scaling and nonparametric multivariate statistical procedures, including analysis of similarity and similarity percentage routines, were used to compare arthropod and vegetation community composition and ground-cover characteristics between habitats. Arthropod communities in the rehabilitated habitat were distinct from those observed in the undisturbed and weed-infested habitats. Rehabilitation in this study resulted in a shift toward conditions observed in an undisturbed habitat and perhaps is an intermediate step to complete restoration. Arthropod richness, arthropod and vegetation community composition, and ground-cover characteristics were all useful indicators but returned slightly different results. Assessing multiple variables yielded the most complete understanding of the habitats studied.
\end{abstract}

Key words: ecological indicators, arthropod community composition, land-rehabilitation monitoring.

The invasion of Bromus tectorum L. (cheatgrass), an exotic annual grass species, has contributed to rangeland degradation in sagebrush-steppe biomes (Knapp 1996). Impacts of B. tectorum infestation include a shift in the fire regime of affected areas: sagebrush communities that historically burned every $60-110$ years may experience fire every 5 years following the invasion of B. tectorum (Roberts 1990, Whisenant 1990). This shorter fire cycle retards or prevents recruitment of native plants. Bromus tectorum also competes with native plants for water or other resources, thereby reducing native-plant production (Melgoza et al. 1991, Ogle et al. 2003). Thus, B. tectorum invasion can effect a shift from a native-plant community to a $B$. tectorum-dominated community approaching or reaching a monoculture (Whisenant 1990). This shift in vegetation can lead to reduced faunal as well as floral diversity (Roberts 1990) and has threatened important habitats, including biggame winter range (Updike et al. 1990).

The objectives of rangeland-rehabilitation (especially fire-rehabilitation) efforts include protecting life and property and minimizing unacceptable degradation of natural and cultural resources (USDA Forest Service 2004) by reducing erosion and limiting the invasion of undesirable annual species (Pellant 1990, Beyers 2004). Such efforts have historically involved planting nonnative perennial species (Harris and Dobrowolski 1986, Roundy 1997, Beyers 2004). The use of nonnative species in land rehabilitation alters the successional trajectories of seeded areas (Christian and Wilson 1999, Bakker and Wilson 2004) and introduces a new type of disturbed community. Nonnative plant species may compete with native plants and could thereby preclude recovery of nativevegetation communities (Beyer 2004). Recently, the use of native plants and seeds from locally collected sources has been advocated (USDA Forest Service 2004), demonstrating increased interest in restoring native-plant communities. Even when native species are used in rehabilitation efforts, resulting vegetation communities may still differ from undisturbed communities due to the use of "native-but-not-resident"

1Department of Plant and Wildlife Science, Brigham Young University, 275 WIDB, Provo, UT 84602

${ }^{2}$ E-mail: eric.t.gardner@gmail.com 
species (Parmenter and MacMahon 1990). Rehabilitation represents an additional disturbance to rangelands that may or may not contribute to the development of vegetation similar to predisturbance plant communities or produce a shift in successional trajectories toward a natural condition (Parmenter and MacMahon 1990, Burger et al. 2003).

Though many rehabilitation and restoration projects have been implemented, relatively few have been evaluated relative to their success in restoring ecosystem integrity (RuizJaen and Aide 2005a). When restoration success has been assessed, the evaluations have most commonly been based on attributes of vegetation, such as diversity and structure (Ruiz-Jaen and Aide 2005a, Herrick et al. 2006). Many have suggested that restoration success should be monitored with respect to the entire ecosystem, not just the vegetation (Block et al. 2001, Longcore 2003, Ruiz-Jaen and Aide 2005b).

Arthropods have been suggested as valuable ecological indicators and indicators of restoration/rehabilitation success (Kremen et al. 1993, Burger et al. 2003, Karr and Kimberling 2003). Despite the challenges of limited baseline data, identification expertise, and knowledge of the natural histories of many arthropods (McIntyre et al. 2001, Longcore 2003), several characteristics contribute to the utility of arthropods as ecological indicators. The small size and short generation times of arthropods make them sensitive to even subtle changes in habitat quality; arthropods also occupy a wide range of habitats and perform diverse ecological roles (Kremen et al. 1993, Burger et al. 2003, Longcore 2003). Because of these characteristics, arthropods can act as indicators of ecosystem health to some degree (Burger et al. 2003). Some studies investigate a single arthropod taxon; others suggest that examining multiple taxa can yield a better understanding of complex ecosystems (Mattoni et al. 2000, Carignan and Villard 2002, Karr and Kimberling 2003, Longcore 2003, Nichols and Nichols 2003).

We describe a case study evaluating the ecological impact of B. tectorum invasion following fire disturbance and the effectiveness of revegetation as a means of rehabilitation of a degraded semiarid shrubsteppe system. These evaluations were accomplished using measurements of arthropod richness, arthropod and vegetation community composition, and ground-cover characteristics in 3 habitats: undisturbed, burned and weed infested (B. tectorum), and burned then rehabilitated with native and nonnative vegetation. Our objectives were to (1) provide insight into the ecological changes that can occur as a result of B. tectorum infestation and land rehabilitation following fire disturbance and (2) determine the suitability of the indicators used here as ecological monitors in this system.

\section{Methods \\ Study Site}

The study site was located near the southern end of the Cedar Mountains in western Utah on Dugway Proving Grounds, approximately $100 \mathrm{~km}$ southwest of Salt Lake City at $40^{\circ} 15^{\prime} 13.74^{\prime \prime} \mathrm{N}, 112^{\circ} 49^{\prime} 09.01^{\prime \prime} \mathrm{W}$. Historically, vegetation in the area was typical of a sagebrush-steppe biome. The study area receives $20-30 \mathrm{~cm}$ of precipitation annually, has a frostfree period varying from 100 to 140 days, and consists of soil characterized in the Hiko Peak-Checkett complex. Such soil has a moderate potential for seedling survival, a moderate potential for damage by fire (i.e., damage to nutrient, physical, and biotic soil characteristics), and a slight erosion hazard (Soil Survey Staff 2007).

In 1994, a fire burned through a portion of the study area, removing much of the sagebrush (Artemisia tridentata Nutt.) from the affected region. Part of the burned area was subsequently rehabilitated by drill seeding native and nonnative shrubs and grasses. The remainder of the burned area was not treated and is now dominated by B. tectorum $\mathrm{L}$. Thus, the site contains 3 adjacent areas representing 3 habitats: undisturbed, weed infested, and rehabilitated.

The undisturbed habitat provided a useful reference to compare with the weed-infested and rehabilitated habitats. Though the undisturbed habitat could not be characterized as pristine due to the presence of B. tectorum and other weed species, it included an intact shrub component representative of conditions in the absence of fire. The undisturbed habitat exhibited an ecological condition that the system apparently could support, and thus, this habitat could be used to define a theoretically plausible goal for restoration efforts in adjacent areas and could serve as a valuable model community (Parmenter and MacMahon 1990). 


\section{Arthropod Sampling}

Pitfall traps were used to sample terrestrial arthropods from each of the 3 habitats representing undisturbed, weed-infested, and rehabilitated conditions. Traps consisted of 2 plastic 0.5-L cylindrical containers with diameters of $10 \mathrm{~cm}$. Containers were nested together to facilitate removal and replacement of the upper container when specimens were collected. The containers were buried such that the lip of the upper container was even with the soil surface. The traps were installed in arrays of 9 traps arranged in 3 rows of 3 traps each. Each trap was $10 \mathrm{~m}$ from its nearest neighbor (see Pik et al. 1999, Schnell et al. 2003). Three arrays of 9 traps each were placed in each of the 3 habitats sampled, yielding a total of 27 traps in each habitat (i.e., 81 traps in all habitats combined). Trapping periods were 24 hours long during which time all traps were active. Active traps were filled one-third full with water; dish soap was added to break the surface tension and thereby reduce the probability of captured arthropods escaping. A $20 \times$ 20 -cm piece of plywood supported $2 \mathrm{~cm}$ above the surface of the soil on wooden blocks was placed over the traps to reduce water evaporation from the trap, occurrence of nontarget organisms, and contamination of the trap by rain or windblown debris. Traps were active for 11 trapping periods during the summer of 2003 (12 Jun, 19 Jun, 10 Jul, 17 Jul, 24 Jul, 31 Jul, 7 Aug, 14 Aug, 21 Aug, 28 Aug, and 4 Sep), and 8 trapping periods during the summer of 2004 (26 May, 9 Jun, 22 Jun, 7 Jul, $20 \mathrm{Jul}, 4$ Aug, 18 Aug, and 31 Aug). After each 24-hour trapping period, arthropods were collected from each trap and preserved in $70 \%$ ethyl alcohol.

Of the arthropods caught in the traps, those primarily limited to ground-dwelling habits were selected for analysis (McIntyre et al. 2001, Ausden and Drake 2006). Though highly mobile insects such as flies and wasps did occur in the traps, these were not included in this analysis because the sampling procedures were designed to target ground-dwelling arthropods, and capture rates of other insects may not accurately represent localized populations. Further justification for restricting the analysis to arthropods with fairly limited mobility stems from the relatively close proximity of the habitats being compared. Insects that regularly fly significant distances may have come from sources beyond the boundaries of each habitat. This study focused on arthropods more closely tied to specific and localized environmental conditions.

Arthropods chosen for analysis were identified to the lowest taxonomic level practical (Ellis et al. 2000). Insects were identified to the family level, following Triplehorn and Johnson (2005). Noninsect arthropods were identified to order. Individuals in the families Tenebrionidae (Coleoptera) and Tettigoniidae (Orthoptera) were identified to species. The total number of arthropods in each of the taxa described above was determined for each trap in each trapping period. Abundance data were summed within trap arrays and averaged across trapping events within years to yield 6 samples from each habitat that were used to describe terrestrial arthropod community composition (see subsequent subsection on community composition analysis).

Taxonomic richness was compared between habitats within years and between years within habitats. Because the number of individuals sampled varied between habitats and between years, comparisons of taxon richness were made using individual-based rarefaction curves (see Gotelli and Colwell 2001). These curves were created using the Species Diversity procedure in EcoSim700 with 1000 iterations and independent sampling (Gotelli and Entsminger 2001). Data used to create the curves consisted of taxon abundance data combined across traps and arrays within habitats.

Vegetation and Ground-Cover Sampling

Vegetation data were collected from locations of each pitfall trap array. This was accomplished along four 20-m transects arranged in the cardinal directions from the center pitfall trap. Ground-cover and aerial-cover data were assessed using 0.25- $\mathrm{m}^{2}$ 8-point quadrats placed at regular intervals $(4 \mathrm{~m})$ along each transect.

Percent ground cover occupied by bare ground, plant litter, plant crown, and cryptogamic crust was estimated by recording the cover type directly below each of the 8 points on the frame at each sampling location. Average percent ground cover for each category in each array location and the total percent ground cover within each habitat was computed by dividing the total number of occurrences of each ground-cover category by the total possible occurrences. These data were analyzed 
TABLE 1. Average abundance of each arthropod taxon in each habitat in each year and species richness.

\begin{tabular}{|c|c|c|c|c|c|c|}
\hline \multirow[b]{2}{*}{ Taxon } & \multicolumn{2}{|c|}{ Weed-infested } & \multicolumn{2}{|c|}{ Rehabilitated } & \multicolumn{2}{|c|}{ Undisturbed } \\
\hline & 2003 & 2004 & 2003 & 2004 & 2003 & 2004 \\
\hline Acari & 1.36 & 3.00 & 1.55 & 1.63 & 3.91 & 2.00 \\
\hline Anabrus simplex Haldeman & 7.00 & 11.00 & 1.55 & 1.50 & 0.09 & 0.13 \\
\hline Araneae & 35.45 & 19.00 & 13.82 & 18.25 & 6.91 & 12.50 \\
\hline Carabidae & 1.45 & 4.38 & 0.09 & 0.38 & 0.00 & 0.00 \\
\hline Curculionidae & 0.00 & 0.00 & 0.00 & 0.13 & 0.00 & 0.50 \\
\hline Formicidae & 67.73 & 32.38 & 35.27 & 58.75 & 51.82 & 56.63 \\
\hline Gryllidae & 1.36 & 0.63 & 1.36 & 0.88 & 0.45 & 0.13 \\
\hline Isoptera & 10.45 & 0.25 & 0.09 & 0.00 & 0.18 & 0.00 \\
\hline Machilidae & 0.09 & 0.50 & 0.00 & 0.00 & 2.36 & 4.25 \\
\hline Mutillidae & 0.18 & 0.00 & 0.82 & 0.00 & 1.91 & 0.13 \\
\hline Pseudoscorpiones & 0.18 & 0.00 & 0.64 & 0.13 & 0.36 & 0.50 \\
\hline Rhaphidophoridae & 1.27 & 1.38 & 4.55 & 3.50 & 4.73 & 10.50 \\
\hline Scorpionida & 2.82 & 1.63 & 1.36 & 1.50 & 2.09 & 3.38 \\
\hline Solifugae & 0.36 & 0.88 & 0.82 & 0.25 & 1.82 & 1.25 \\
\hline Staphylinidae & 0.18 & 0.13 & 0.00 & 0.00 & 0.00 & 0.00 \\
\hline Stenopelmatidae & 0.18 & 0.00 & 0.00 & 0.00 & 0.00 & 0.00 \\
\hline Blapstinus sp. & 6.55 & 2.63 & 0.09 & 0.25 & 0.18 & 0.50 \\
\hline Coniontis sp. & 0.82 & 0.00 & 0.00 & 0.00 & 0.00 & 0.00 \\
\hline Edrotes ventricosus & 0.09 & 0.00 & 0.00 & 0.00 & 0.00 & 0.00 \\
\hline Eleodes extricata & 0.64 & 0.38 & 0.09 & 0.00 & 0.09 & 0.00 \\
\hline Eleodes hispilabris & 1.73 & 1.25 & 1.55 & 1.00 & 1.09 & 0.25 \\
\hline Eleodes longicollis & 0.09 & 0.25 & 0.00 & 0.00 & 0.00 & 0.38 \\
\hline Eleodes obscurus & 1.00 & 0.75 & 1.36 & 0.88 & 0.64 & 0.25 \\
\hline Eusattus muricatus & 0.09 & 0.00 & 0.00 & 0.00 & 0.00 & 0.00 \\
\hline Steriphanus sp. & 3.73 & 0.00 & 0.00 & 0.00 & 0.09 & 0.00 \\
\hline Other Tenebrionidae & 0.64 & 0.00 & 0.27 & 0.00 & 0.00 & 0.00 \\
\hline Total & 145.45 & 80.38 & 65.27 & 89.00 & 78.73 & 93.25 \\
\hline Richness & 25 & 17 & 17 & 14 & 17 & 16 \\
\hline
\end{tabular}

simultaneously using the same multivariate techniques for analysis of community composition described below.

Ocular estimates of aerial-cover class were given for each species contributing to canopy cover in each quadrat. Cover classes were 1 (0-1\% cover), 2 ( $1-5 \%$ cover), 3 (5-15\% cover), 4 (15-25\% cover), 5 (25-50\% cover), 6 (50-75\% cover), 7 (75-95\% cover), and 8 (95-100\% cover). Cover class midpoints were used to calculate average aerial cover (and standard errors) by species for each array location and for all array locations within each habitat combined. Aerial-cover data from each trap-array location were used to characterize vegetation community composition.

\section{Community Composition Analysis}

Arthropod and vegetation community compositions were characterized (separately) from the data described above using the statistical package Primer v6 (Clark and Gorley 2006). To reduce the influence of highly abundant taxa, all data were square-root transformed (Clark and Warwick 2001). A resemblance matrix was created by calculating Bray-Curtis similarities for each pairwise comparison of trap-array data. Nonmetric multidimensional scaling (NMDS) plots were used to graphically represent the data in the resulting resemblance matrices. Differences in community composition were tested for significance using an analysis of similarities procedure (ANOSIM in Primer v6). A 2-way crossed ANOSIM procedure was used to test for significant differences in arthropod community composition in habitat groups and year groups simultaneously. Because vegetation and ground-cover data were collected only once, a one-way ANOSIM was performed to test for significant differences in vegetation community composition between habitats.

To determine the percent contribution of each variable being analyzed to within-group similarity and to between-group dissimilarity, a similarities-percentages procedure (SIMPER) in Primer v6 was used (Clark and Gorley 2006). The percent contribution of each arthropod taxon to similarity within habitats and years and to dissimilarity between habitats and 
between years was determined using a 2-way SIMPER procedure based on the Bray-Curtis index of similarity. The percent contribution of each plant species to within-habitat similarity and between-habitat dissimilarity was assessed using a one-way SIMPER procedure. A oneway SIMPER procedure was also used to assess the percent contribution of each groundcover variable to within-habitat similarity and between-habitat dissimilarity.

\section{Relating Arthropod and Environmental Data}

The RELATE function in Primer v6 (Clark and Gorley 2006), using the Spearman rank correlation method and 999 permutations, was used to test for relatedness between the observed communities. Relatedness was tested between the resemblance matrix representing the arthropod community and matrices representing the vegetation community and groundcover variables, and a resemblance matrix including both vegetation and ground-cover data.

\section{RESULTS}

\section{Arthropod Richness}

A total of 5285 terrestrial arthropods representing 26 taxa (Table 1) were caught during the 2 years of sampling (3184 in 2003 and 2101 in 2004). The greatest average abundance of all taxa combined (145.45) was observed in the weed-infested habitat in 2003. In that year, average abundances of 78.73 and 65.27 were observed in the undisturbed and rehabilitated habitats, respectively. In 2004, the greatest average abundance of terrestrial arthropods (93.25) occurred in the undisturbed habitat, followed by the rehabilitated (89.00) and the weed-infested (80.38) habitats.

Differences in terrestrial-arthropod richness were observed between habitats in both 2003 and 2004 as evidenced by the individualbased rarefaction curves (Fig. 1). In both years, observed richness was greater (no overlap in 95\% confidence intervals) in the weed-infested habitat than in either the rehabilitated or the undisturbed habitat. No difference in richness was observed between the undisturbed and rehabilitated habitats in 2003; but in 2004, richness was greater in the undisturbed habitat. Taxa that occurred in the weed-infested habitat but not in either of the other 2 habitats included Coniontis sp., Edrotes ventricosus, and
Eusattus muricatus (Coleoptera: Tenebrionidae), Staphylinidae (Coleoptera), and Stenopelmatidae (Orthoptera).

Differences in taxon richness were observed between years within the rehabilitated and weed-infested habitats (Fig. 2). Both of these habitats displayed lower richness in 2004 than in 2003. No difference in richness was observed in the undisturbed habitat between years.

$$
\text { Arthropod Community Composition }
$$

The NMDS plot of arthropod data had a stress value of 0.09 (Fig. 3). This value was small enough to indicate that this representation was a good depiction of the relationships between the data points (Clarke and Warwick 2001). The NMDS plot showed that points representing trap arrays from any given habitat were plotted close together, indicating within-habitat similarity. Superimposed similarity levels from a group-average cluster dendrogram demonstrated that points representing data from the undisturbed and rehabilitated habitats each grouped together at a $75 \%$ similarity level and that points from the weed-infested habitat grouped together at a $65 \%$ similarity level. That there was no overlap of points representing different habitats demonstrates some dissimilarity between habitats, but all points still grouped together at $60 \%$ similarity. The points representing data from the rehabilitated habitat were plotted between points representing data from the undisturbed and weed-infested habitats indicating that the arthropod community in the rehabilitated habitat was more similar to the communities in both the undisturbed and weed-infested habitats than either of these latter communities were to each other. This pattern suggests that the terrestrial-arthropod community observed in the rehabilitated habitat was intermediate to the communities observed in the other habitats. Communities from the undisturbed and rehabilitated habitats grouped together at $65 \%$ similarity and were more similar to each other than either was to the community from the weed-infested habitat. The NMDS plot also displayed changes in community composition that occurred between years, especially within the weed-infested and rehabilitated habitats. While it is apparent that differences were observed between years, no consistent pattern was evident across all habitats.

As suggested by the NMDS plot, the analysis of similarities procedure showed differences 


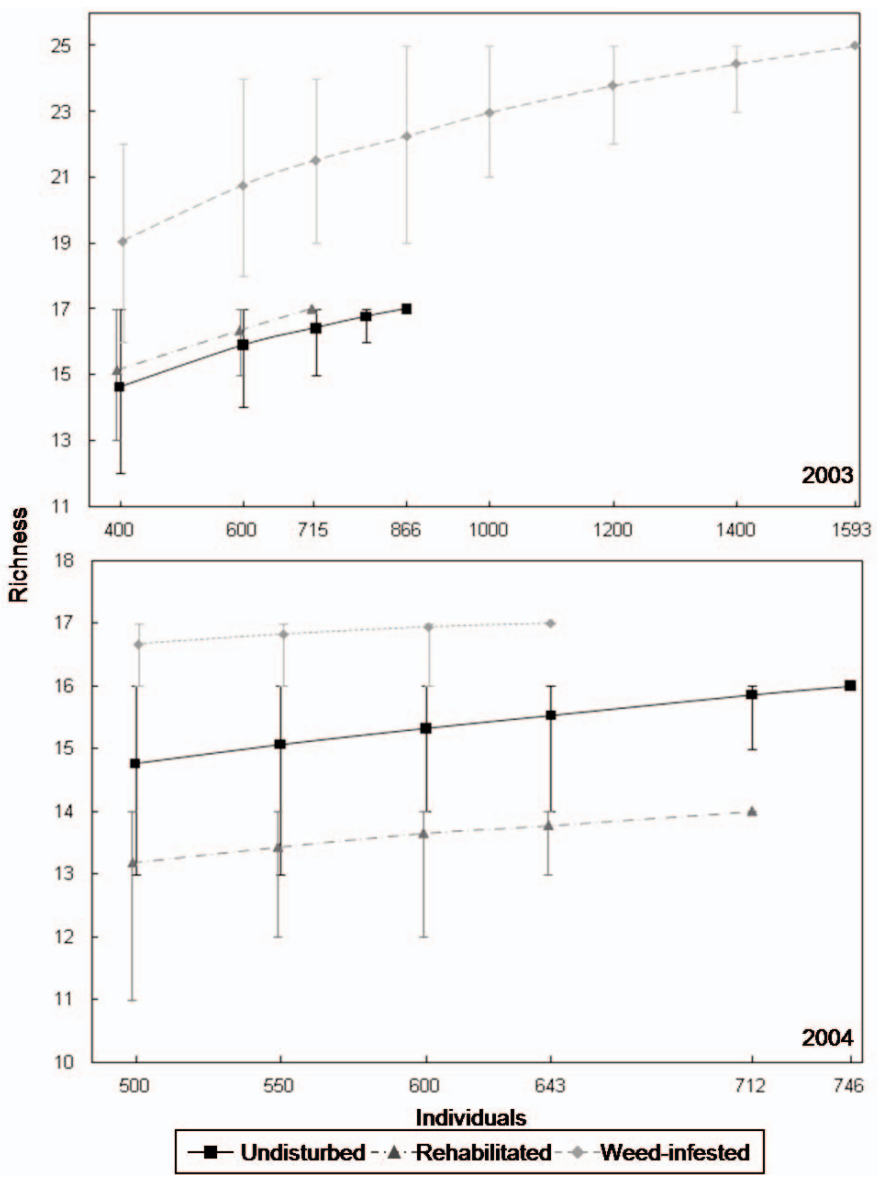

Fig. 1. Individual-based rarefaction curves with 95\% confidence intervals for 2003 and 2004.

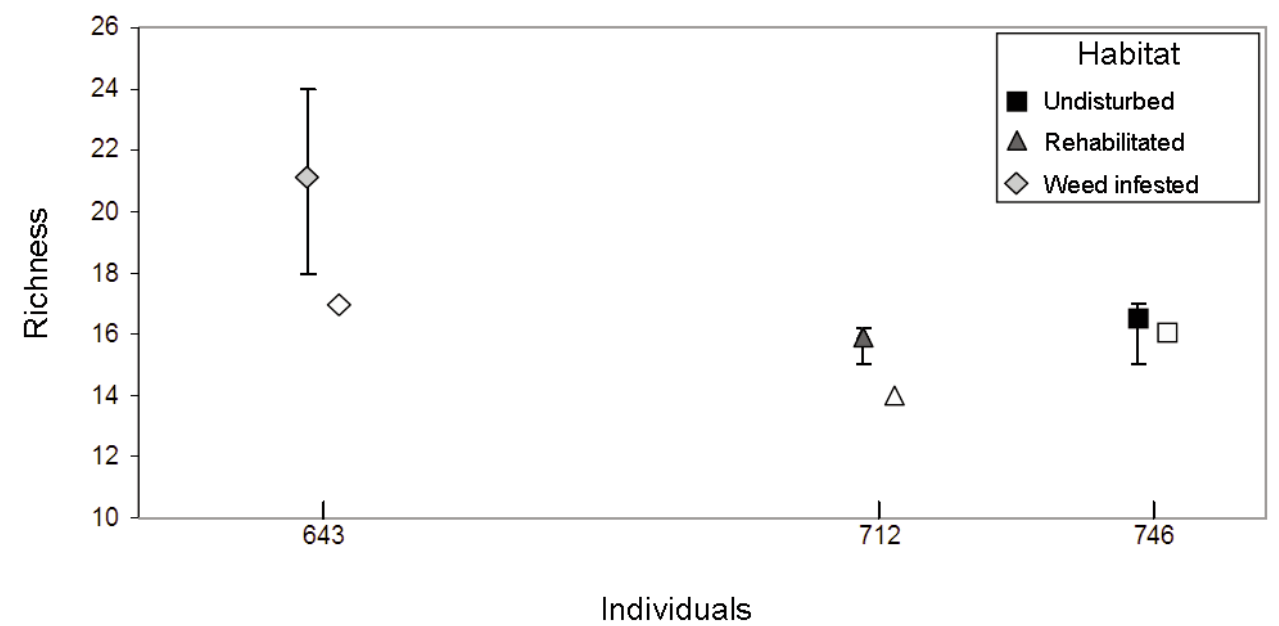

Fig. 2. Arthropod richness with 2003 data (filled symbols) rarified to abundance levels from 2004 (open symbols). Error bars represent $95 \%$ confidence intervals for rarified values. 


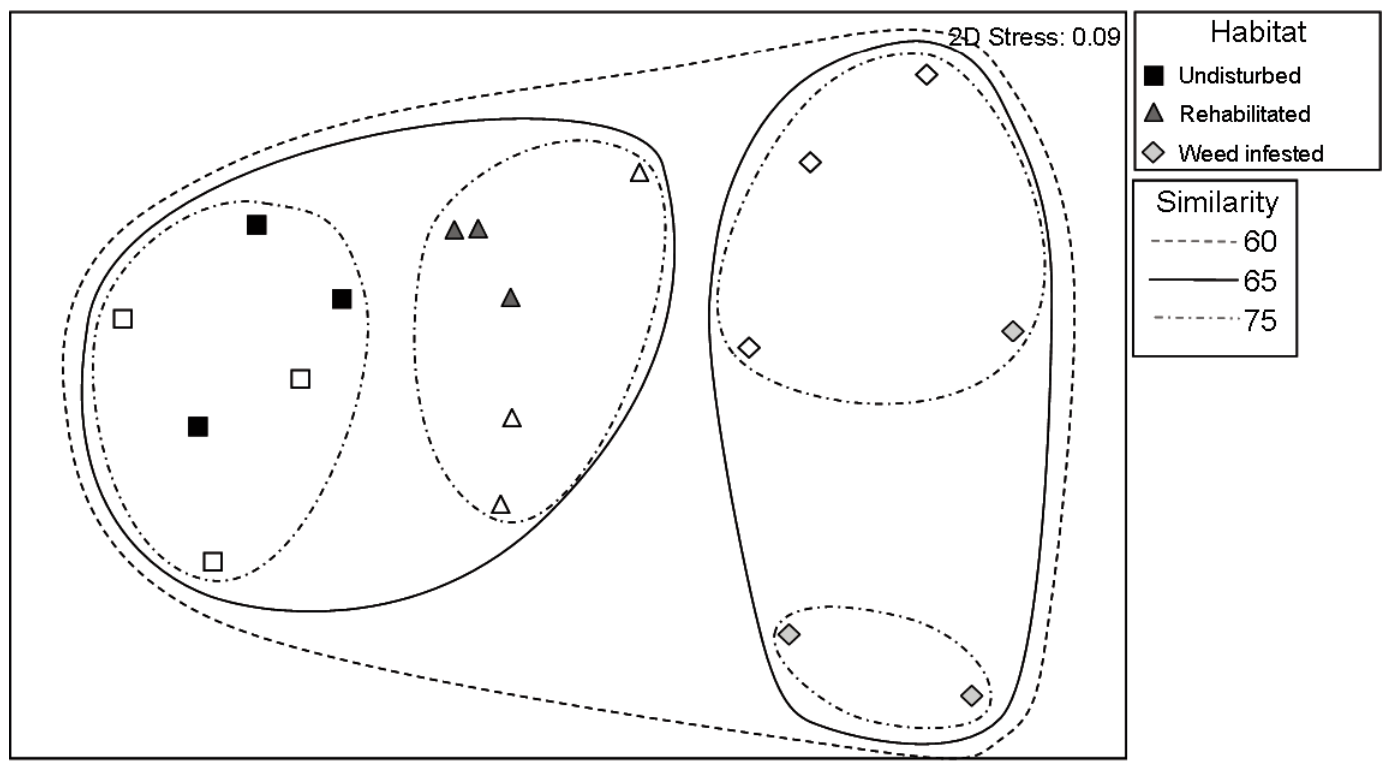

Fig. 3. Nonmetric multidimensional scaling plot of terrestrial arthropod community composition data from 2003 (filled symbols) and 2004 (open symbols) with similarity levels from group-averaged cluster dendrogram.

in community composition between habitats at the $P=0.001$ level $(R=0.848)$ and between years at the $P=0.001$ level $(R=0.519)$. Pairwise comparisons of habitats indicated differences between the weed-infested and rehabilitated habitats at the $P=0.01$ level $(R=0.815)$, between the weed-infested and undisturbed habitats at the $P=0.01$ level $(R=$ $1)$, and between the rehabilitated and undisturbed habitats at the $P=0.01$ level $(R=$ 0.944 ).

The results of the SIMPER procedure (Table 2) indicate that the dissimilarity in arthropod communities between the weed-infested and rehabilitated habitats is attributable primarily to differences in average abundance of Formicidae (Hymenoptera) between habitats and to the lower average abundance of Blapstinus sp. (Coleoptera: Tenebrionidae), Anabrus simplex (Orthoptera: Tettigoniidae), Araneae, Carabidae (Coleoptera), Isoptera, and Steriphanus sp. (Coleoptera: Tenebrionidae) and the greater average abundance of Rhaphidophoridae in the rehabilitated habitat than in the weed-infested habitat. Differences between arthropod communities in the weed-infested and undisturbed habitats were attributable to lower average abundances of A. simplex, Araneae, Blapstinus sp., and Carabidae and greater average abundances of Formicidae, Rhaphidophoridae, and
Machilidae in the undisturbed habitat than in the weed-infested habitat. Differences in arthropod communities between the rehabilitated and undisturbed habitats were attributable to greater average abundances of Machilidae, Formicidae, Rhaphidophoridae, and Acari and lower average abundances of A. simplex, Araneae, and Gryllidae in the undisturbed habitat than in the rehabilitated habitat. Taxa contributing to arthropod community dissimilarity between years (Table 3 ) include Formicidae, Araneae, Mutillidae, and Isoptera, each of which had lower average abundance in the second year, and A. simplex, which had a greater average abundance in the second year.

\section{Vegetation Community Composition}

Sixteen plant species were observed in the vegetation sampling procedures (Table 4 ). The greatest richness (13 species) was seen in the rehabilitated habitat, followed by the undisturbed (9 species) and weed-infested (4 species) habitats. Higher richness in the rehabilitated habitat was due mostly to the presence of species seeded as part of the rehabilitation process. Average aerial cover of all plant species combined was greatest in the weedinfested habitat (55\%), followed by the undisturbed and rehabilitated habitats $(26 \%$ and $17 \%$, respectively). 
TABLE 2. Contribution (\%) of arthropod taxa to between-habitat dissimilarity.

\begin{tabular}{lccc}
\hline Taxon & $\begin{array}{c}\text { Undisturbed and } \\
\text { weed-infested }\end{array}$ & $\begin{array}{c}\text { Undisturbed and } \\
\text { rehabilitated }\end{array}$ & $\begin{array}{c}\text { Rehabilitated and } \\
\text { weed-infested }\end{array}$ \\
\hline Anabrus simplex & 12.58 & 8.83 & 10.09 \\
Formicidae & 9.77 & 12.50 & 14.30 \\
Araneae & 9.22 & 7.72 & 7.68 \\
Blapstinus sp. & 7.54 & 3.19 & 10.36 \\
Rhaphidophoridae & 7.51 & 6.32 & 5.20 \\
Carabidae & 7.11 & 2.87 & 7.36 \\
Machilidae & 6.64 & 14.49 & 1.87 \\
Isoptera & 4.67 & 1.30 & 5.81 \\
Steriphanus sp. & 3.76 & 0.74 & 2.91 \\
Acari & 3.20 & 5.35 & 2.08 \\
Eleodes hispilabris & 3.07 & 4.41 & 1.72 \\
Mutillidae & 2.85 & 2.98 & 3.58 \\
Eleodes extricata & 2.79 & 0.98 & 2.98 \\
Gryllidae & 2.64 & 5.42 & 1.85 \\
Pseudoscorpiones & 2.31 & 3.01 & 3.06 \\
Eleodes obscurus & 2.30 & 4.90 & 2.50 \\
Solifugae & 2.12 & 4.79 & 2.85 \\
Scorpiones & 1.96 & 4.29 & 1.41 \\
Eleodes longicollis & 1.54 & 2.13 & 1.87 \\
Coniontis sp. & 1.49 & 0.00 & 1.40 \\
Other Tenebrionidae & 1.27 & 1.77 & 1.41 \\
Stenopelmatinae & 1.11 & 0.00 & 0.64 \\
Curculionidae & 1.03 & 2.03 & 0.99 \\
Staphylinidae & 0.79 & 0.00 & 0.47 \\
Eusattus muricatus & 0.38 & 0.00 & 0.43 \\
Edrotes ventricosus & 0.35 & 0.00 &
\end{tabular}

TABLE 3. Arthropod data including average abundance of each taxon and contribution (\%) of each taxon to dissimilarity between years.

\begin{tabular}{lccc}
\hline & \multicolumn{2}{c}{ Average abundance } & $\begin{array}{c}\text { Contribution to } \\
\text { dissimilarity }\end{array}$ \\
\cline { 2 - 4 } Taxon & 2003 & 2004 & 2003 and 2004 \\
\hline Formicidae & 154.82 & 147.75 & 15.13 \\
Araneae & 56.18 & 49.75 & 8.05 \\
Mutillidae & 2.91 & 0.13 & 6.55 \\
Isoptera & 10.73 & 0.25 & 5.38 \\
Anabrus simplex & 8.64 & 12.63 & 5.89 \\
Steriphanus sp. & 3.82 & 0.00 & 4.78 \\
Blapstinus sp. & 6.82 & 3.38 & 4.73 \\
Gryllidae & 3.18 & 1.63 & 4.47 \\
Acari & 6.82 & 6.63 & 4.44 \\
Rhaphidophoridae & 10.55 & 15.38 & 4.37 \\
Eleodes obscurus & 3.00 & 1.88 & 4.33 \\
Eleodes hispilabris & 4.36 & 2.50 & 4.17 \\
Carabidae & 1.55 & 4.75 & 3.87 \\
Machilidae & 2.46 & 4.75 & 3.33 \\
Scorpiones & 6.27 & 6.50 & 3.27 \\
Solifugae & 3.00 & 2.38 & 3.15 \\
Pseudoscorpiones & 0.63 & 3.11 \\
Other Tenebrionidae & 0.18 & 0.60 & 2.20 \\
Eleodes longicollis & 0.91 & 0.63 & 1.77 \\
Curculionidae & 0.09 & 0.63 & 1.58 \\
Eleodes extricata & 0.00 & 0.38 & 1.54 \\
Coniontis sp. & 0.82 & 0.00 & 0.81 \\
Staphylinidae & 0.82 & 0.00 & 0.72 \\
Stenopelmatinae & 0.18 & 0.13 & 0.39 \\
Eusattus muricatus & 0.18 & 0.00 & 0.36 \\
Edrotes ventricosus & 0.09 & & \\
\hline
\end{tabular}


TABLE 4. Average vegetation aerial cover (\%) and standard errors (in parentheses) for the habitats.

\begin{tabular}{|c|c|c|c|}
\hline Species & Undisturbed & Rehabilitated & Weed-infested \\
\hline Picrothamnus desertorum Nutt. & - & $0.01(0.01)$ & - \\
\hline Artemisia tridentata Nutt. & $11.4(2.1)$ & $4(1.4)$ & - \\
\hline Atriplex canescens (Pursh) Nutt. & - & $0.7(0.6)$ & - \\
\hline Atriplex confertifolia (Torr. \& Frém.) S. Watson & $1.7(0.9)$ & $0.05(0.05)$ & - \\
\hline Ericameria nauseosa (Pall. ex Pursh) G.L. Nesom \& Baird & - & $5(1.7)$ & - \\
\hline Chrysothamnus viscidiflorus (Hook.) Nutt. & $0.2(0.2)$ & - & - \\
\hline SHRUB TOTAL & $13.3(2.3)$ & $9.7(2.3)$ & - \\
\hline Phlox hoodii Richardson & - & $0.1(0.07)$ & - \\
\hline Sphaeralcea munroana (Douglas) Spach & - & - & $0.02(0.01)$ \\
\hline FORB TOTAL & - & $0.1(0.07)$ & $0.02(0.01)$ \\
\hline Agropyron cristatum (L.) Gaertn. & - & $3(0.6)$ & - \\
\hline Elymus elymoides (Raf.) Swezey & $0.08(0.1)$ & $0.3(0.1)$ & - \\
\hline Poa secunda J. Presl & $0.01(0.01)$ & $1.6(0.5)$ & - \\
\hline Achnatherum hymenoides (Roem. \& Schult.) Barkworth & $0.45(0.2)$ & $0.01(0.01)$ & - \\
\hline PERENNIAL GRASS TOTAL & $0.5(0.2)$ & $4.9(0.9)$ & - \\
\hline Bromus tectorum L. & $12.3(2.2)$ & $2.3(0.8)$ & $54.6(3.1)$ \\
\hline Ceratocephala testiculata (Crantz) Roth & $0.1(0.03)$ & $0.1(0.02)$ & $0.01(0.01)$ \\
\hline Salsola tragus $\mathrm{L}$. & - & $0.01(0.01)$ & $0.5(0.2)$ \\
\hline Sisymbrium altissimum L. & $0.01(0.01)$ & - & - \\
\hline ANNUAL WEED TOTAL & $12.4(2.2)$ & $2.3(0.8)$ & $55.1(3.02)$ \\
\hline
\end{tabular}

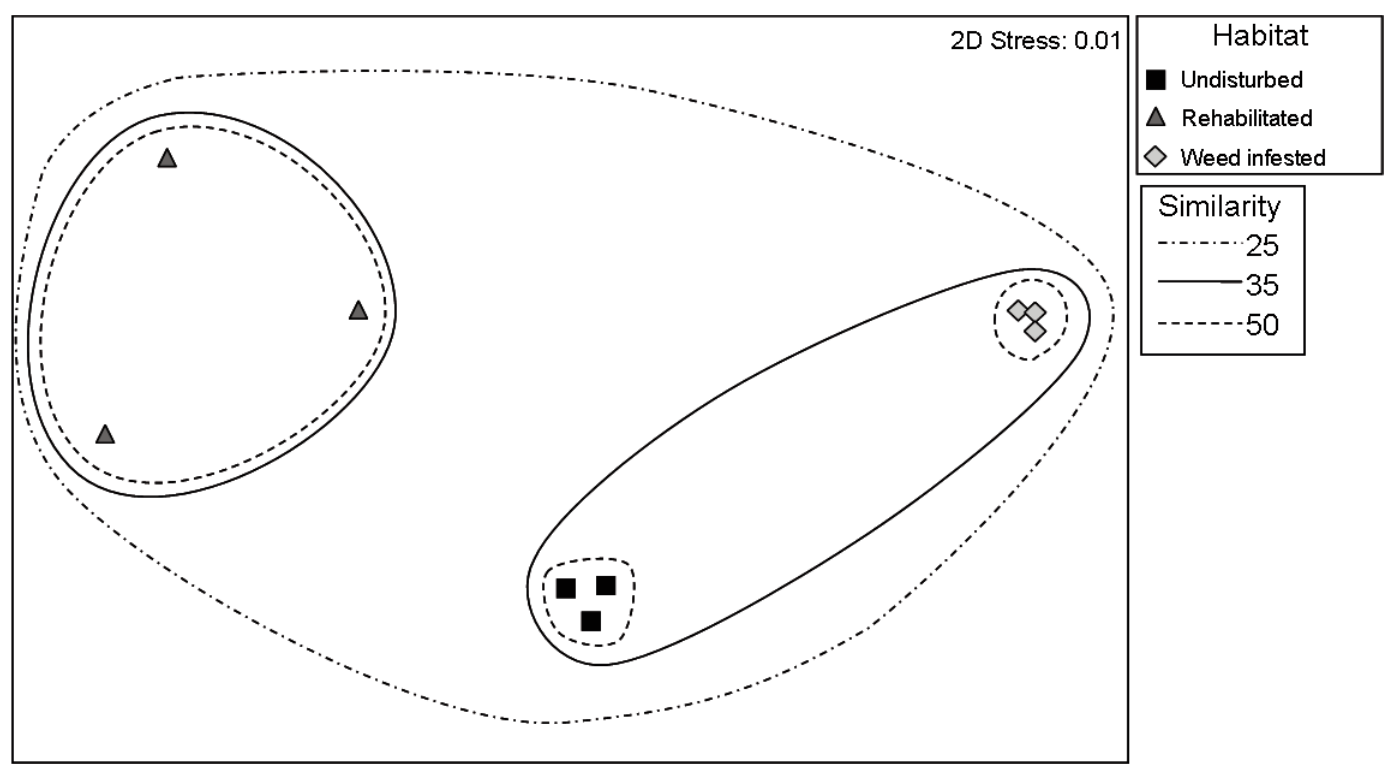

Fig. 4. Nonmetric multidimensional scaling plot of vegetation aerial cover data with similarity levels from group-averaged cluster dendrogram.

The NMDS plot of the data on vegetation community composition showed that samples from each habitat were plotted closer to each other than to samples from other habitats (Fig. 4). The similarity within groups was further demonstrated by the superimposed similarity levels from a group-average cluster dendrogram. Points representing vegetation data within each habitat grouped together at 50\% similarity. Vegetation from the undisturbed and weed-infested habitats grouped together at a greater similarity level $(35 \%)$ than either habitat grouped with vegetation from the rehabilitated habitat. All habitats grouped together at $25 \%$ similarity.

The ANOSIM test showed differences in vegetation community composition between 
TABLE 5. Contributions (\%) of plant species to community dissimilarity between habitats.

\begin{tabular}{lccc}
\hline Species & $\begin{array}{c}\text { Undisturbed and } \\
\text { weed-infested }\end{array}$ & $\begin{array}{c}\text { Undisturbed and } \\
\text { rehabilitated }\end{array}$ & $\begin{array}{c}\text { Rehabilitated and } \\
\text { weed-infested }\end{array}$ \\
\hline Bromus tectorum L. & 36.27 & 17.49 & 39.82 \\
Artemisia tridentata Nutt. & 30.93 & 12.67 & 11.98 \\
Atriplex confertifolia (Torr. \& Frém.) S. Watson & 12.16 & 9.76 & 0.91 \\
Salsola tragus L. & 6.25 & 0.4 & 4.14 \\
Achnatherum hymenoides (Roem. \& Schult.) Barkworth & 5.1 & 4.14 & 0.36 \\
Chrysothamnus viscidiflorus (Hook.) Nutt. & 3.26 & 2.93 & 0 \\
Ceratocephala testiculata (Crantz) Roth & 2.7 & 1.17 & 1.37 \\
Elymus elymoides (Raf.) Swezey & 1.36 & 3.16 & 2.23 \\
Sphaeralcea munroana (Douglas) Spach & 0.98 & 0 & 0.7 \\
Poa secunda J. Presl & 0.54 & 8.5 & 7.14 \\
Sisymbrium altissimum L. & 0.45 & 0.41 & 0 \\
Ericameria nauseosa (Pall. ex Pursh) G.L. Nesom \& Baird & 0 & 18.22 & 14.52 \\
Agropyron cristatum (L.) Gaertn. & 0 & 13.9 & 11.06 \\
Atriplex canescens (Pursh) Nutt. & 0 & 4.68 & 3.71 \\
Phlox hoodii Richardson & 0 & 2.13 & 1.69 \\
Picrothamnus desertorum Nutt. & 0 & 0.45 & 0.36 \\
\hline
\end{tabular}

TABLE 6. Ground cover (\%) with standard errors in parentheses.

\begin{tabular}{lrrr}
\hline Category & Undisturbed & Rehabilitated & Weed-infested \\
\hline Bare ground & $29.79(0.037)$ & $40(0.033)$ & $4.375(0.013)$ \\
Litter & $55(0.039)$ & $45(0.032)$ & $88.54(0.021)$ \\
Plant crown & $3.75(0.009)$ & $3.542(0.009)$ & $6.458(0.018)$ \\
Cryptogam & $11.46(0.025)$ & $11.46(0.019)$ & $0.208(0.002)$ \\
\hline
\end{tabular}

habitats at the $P=0.05$ level. The global $R$ statistic in this case was 1 , the highest possible value, indicating greater similarity within all habitats than between any samples from different habitats. Pairwise tests for significance also returned $R$ statistics of $1(P=0.1)$ for each between-group comparison.

Contributions of each species to betweenhabitat dissimilarity as determined by SIMPER are displayed in Table 5. Differences in the vegetation composition between the undisturbed and weed-infested habitats were primarily attributable to Bromus tectorum, which had a higher percent cover in the weedinfested habitat than in the undisturbed habitat; to Artemisia tridentata, Atriplex confertifolia, and Achnatherum hymenoides, which were present in the undisturbed habitat but were not encountered in the weed-infested habitat; and to Salsola tragus, which was present in the weed-infested habitat but not observed in the undisturbed habitat. The only species in common between the undisturbed and weedinfested habitats were B. tectorum and Ceratocephala testiculata. Differences in vegetation community composition between the undisturbed and rehabilitated habitats were primarily attributable to Ericameria nauseosa; to Agropyron cristatum, which occurred only in the rehabilitated habitat; to Poa secunda, which had a higher percent cover in the rehabilitated habitat; and to B. tectorum, A. tridentata, and A. confertifolia, which had higher percent cover in the undisturbed habitat than in the rehabilitated habitat. Differences between the rehabilitated and weed-infested habitats were primarily attributable to $B$. tectorum, which had a greater percent cover in the weed-infested habitat, and to E. nauseosa, A. tridentata, A. cristatum, and P. secunda, which occurred in the rehabilitated habitat but were not encountered in the weed-infested habitat.

\section{Ground Cover}

Ground-cover data are presented in Table 6. The NMDS plot (Fig. 5) of the ground-cover data showed 2 distinct groups: one consisting of data points from the weed-infested habitat and another consisting of data points from both the undisturbed and rehabilitated habitats. Points from each of these groups clustered together at $75 \%$ similarity according to the superimposed similarity levels from a groupaverage cluster dendrogram; all points grouped together at $60 \%$ similarity. Results of the ANOSIM test confirmed the pattern demonstrated by the NMDS plot. The global $R$ statistic (0.531) indicated differences between habitats at the $P=0.05$ level. Pairwise comparisons of the habitats demonstrated that the differences were between the weedinfested and rehabilitated habitats $(R=0.926$, $P=0.1)$ and between the weed-infested and 


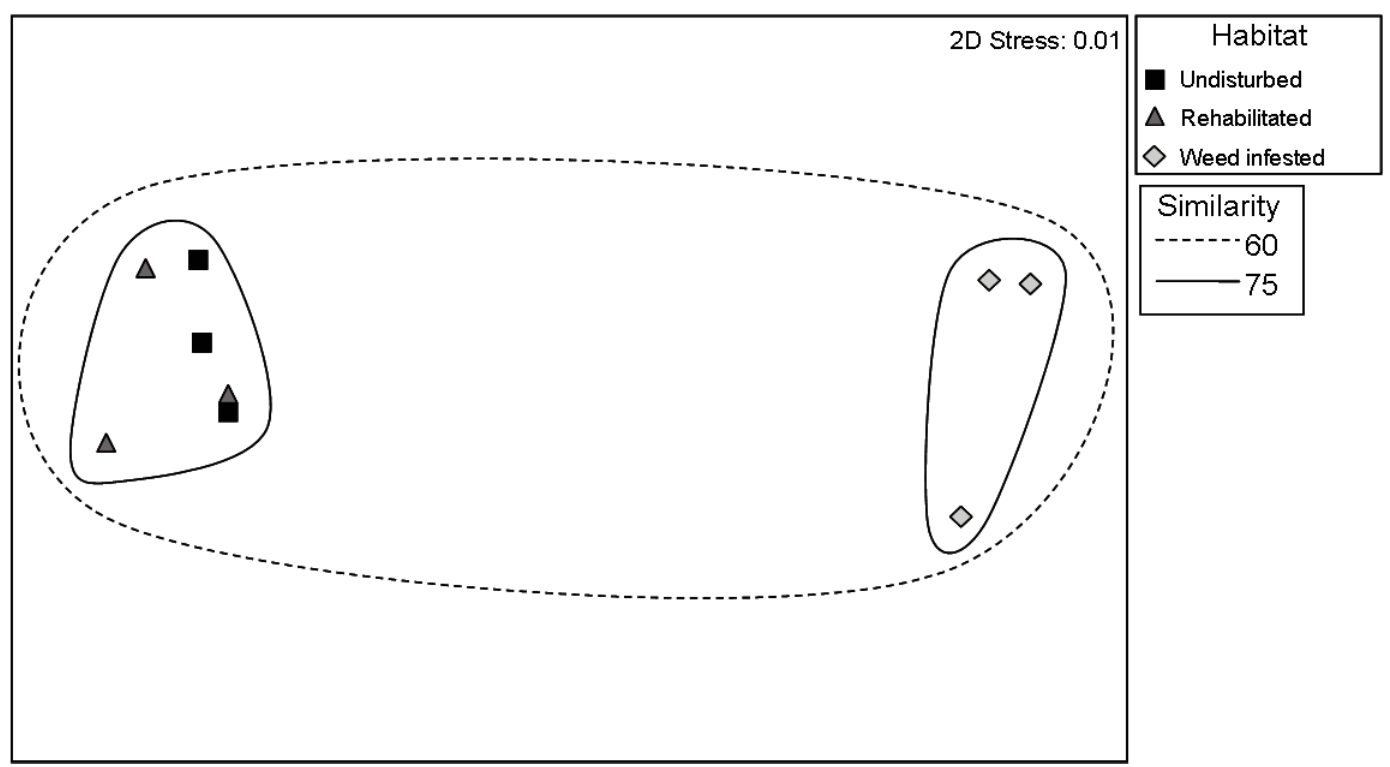

Fig. 5. Nonmetric multidimensional scaling plot of ground cover data with similarity levels from group-averaged cluster dendrogram.

TABLE 7. Ground-cover contribution (\%) to betweenhabitat dissimilarity.

\begin{tabular}{lcc}
\hline Category & $\begin{array}{c}\text { Undisturbed and } \\
\text { weed-infested }\end{array}$ & $\begin{array}{c}\text { Rehabilitated and } \\
\text { weed-infested }\end{array}$ \\
\hline Bare ground & 32.42 & 35.22 \\
Cryptogam & 28.35 & 24.34 \\
Plant crown & 19.86 & 17.16 \\
Litter & 19.38 & 23.28 \\
\hline
\end{tabular}

undisturbed habitats $(R=1, P=0.1)$; pairwise comparison of the rehabilitated and undisturbed habitats showed no difference between these data points. The $R$ statistic in this case was negative $(R=-0.333)$, indicating greater variation within than between these habitats.

Contributions of each ground-cover variable to between-habitat dissimilarity are presented in Table 7. Each of the measured variables contributed to dissimilarity between the weedinfested habitat and each of the other habitats. Plant crown cover and litter cover were greater in the weed-infested habitat than in the other habitats. Cover of cryptogamic crusts and bare ground were greater in both the rehabilitated habitat and undisturbed habitat than in the weed-infested habitat. Because no difference was observed between the undisturbed and rehabilitated habitats, the contributions of each ground-cover variable to dissimilarity between these habitats are not relevant and are therefore not listed.

\section{Relating Arthropod and Environmental Data}

Results of the RELATE procedure indicated a relationship between the terrestrial-arthropod data and the vegetation $(P=0.02)$ and between the arthropod data and the groundcover data $(P=0.01)$. A relationship was also observed between the arthropod data and a resemblance matrix including both vegetation and ground-cover data $(P=0.01)$.

\section{Discussion}

\section{Arthropod Richness}

As in other studies, we found that disturbance significantly impacted arthropod richness (Brehm 1999, Moretti et al. 2006). Even an increase in richness, as observed in the weed-infested habitat in this case, is a departure from an undisturbed condition. Ellis et al. also observed greater richness of some terrestrial-arthropod groups in areas dominated by an exotic plant species (2000). As has been suggested in other areas, greater richness in the weed-infested habitat may be attributable in part to arthropod dispersal from adjacent 
habitats and/or to components of the disturbed habitat that constitute suitable habitat for some taxa (Brehm 1999). That some taxa observed in the weed-infested habitat may have dispersed from adjacent areas rather than being permanent residents is supported by the decrease in richness observed between years in this case.

Varying levels of arthropod richness have been observed in response to rehabilitation/ restoration. Studies have been reported demonstrating greater (e.g., Bisevac and Majer 1999), lesser (e.g., Parmenter and MacMahon 1987, 1990, Parmenter et al. 1991, Anderson and Sparling 1997, Longcore 2003, Lomov et al. 2006), and, as in the current study, equal (e.g., Nichols and Nichols 2003) richness of at least some arthropod taxa in rehabilitated versus undisturbed sites. That the rehabilitated community in this study exhibited the same richness as observed in the undisturbed community supports the idea that rehabilitation can facilitate a shift in arthropod richness toward levels in an undisturbed condition.

The lower terrestrial-arthropod richness in both the weed-infested and rehabilitated habitats in 2004 suggests that richness in these habitats may be less stable than that observed in the undisturbed habitat, where no change in terrestrial-arthropod richness was observed between years. Data from only 2 years of study, however, are admittedly limited, and further research is needed to verify the patterns suggested by these data. Furthermore, while richness data are useful in comparing communities, they do not account for possible differences in community composition.

\section{Arthropod Community Composition}

Differences in arthropod community composition between undisturbed and restored/rehabilitated habitats have been observed on multiple occasions (e.g., Bisevac and Majer 1999, Webb et al. 2000, Burger et al. 2003, Longcore 2003, Nichols and Nichols 2003, Gratton and Denno 2005, Meyer and Whiles 2008). Only a few of these studies have included a comparison with an arthropod community from a disturbed but not rehabilitated site. When such a comparison has been included, as in this study, the arthropod communities from restored sites have also differed from those observed in disturbed habitats (e.g., Longcore 2003, Gratton and Denno 2005). This observed difference supports the idea that manipulation of vegetation can influence arthropod communities. Though different from an undisturbed community, the arthropod community in the rehabilitated habitat was also distinct from that observed in a disturbed habitat and more closely resembled an undisturbed condition. Similar responses have been seen as an improvement and thus at least a partial success of rehabilitation efforts (Bisevac and Majer 1999, Gratton and Denno 2005).

Results of the SIMPER routine identified which taxa contributed most to community dissimilarity between habitat types. Differences between the arthropod community in the weed-infested habitat and the arthropod communities in both the undisturbed and rehabilitated habitats were attributable in part to greater average abundance of A. simplex, Araneae, Blapstinus sp., and Carabidae in the weed-infested habitat. Species in these taxa may fall into the category of "opportunistic "pioneer" - -species described as being abundant in disturbed areas but rare in predisturbance communities or adjacent undisturbed areas (Parmenter and MacMahon 1990). Others have also reported several species that responded positively to disturbance (Brehm 1999, Bess et al. 2002). Two of these taxa, A. simplex and Araneae, were also among the primary contributors to dissimilarity between arthropod communities in the undisturbed and rehabilitated habitats. Each of these groups displayed greater average abundance in the rehabilitated habitat than in the undisturbed habitat. Other influential taxa, including Machilidae and Rhaphidophoridae, were more abundant in the undisturbed habitat than in either the rehabilitated or the weed-infested habitat. Of these, Rhaphidophoridae also contributed to differences between the rehabilitated and weedinfested habitats. The pattern seen in this study for average abundance of Rhaphidophoridae is in contrast to other comparisons of rhaphidophorids in undisturbed sagesteppe versus reclaimed habitats (Parmenter and MacMahon 1990). In this study, A. simplex, Araneae, and Rhaphidophoridae were among the most influential contributors to between-habitat dissimilarity, and the average abundance of each of these taxa in the rehabilitated habitat was intermediate to those observed in the other habitats. Other less influential taxa-Carabidae, Curculionidae, and Mutillidae-showed a similar pattern. These taxa help explain the pattern 
suggested in Fig. 3: that the arthropod community in the rehabilitated habitat is intermediate to the communities observed in the weedinfested and undisturbed habitats. This pattern suggests that while the arthropod community in the rehabilitated habitat is still distinct from that in the undisturbed habitat, it nevertheless represents a shift (perhaps an ongoing shift) away from conditions in a weed-infested habitat and toward conditions in an undisturbed habitat. Additionally, further research into the taxa most responsible for differences between the communities could help identify proximate causes for differences in abundances of these taxa. Rehabilitation practices could then be designed to directly influence those discrepancies and thus increase the likelihood of true restoration, where that is the goal.

Primary contributors to the difference in arthropod community composition between years indicated by the SIMPER procedure included Formicidae, Araneae, Mutillidae, Isoptera, and A. simplex. The overall abundance of A. simplex increased from 2003 to 2004, while the overall abundance of the other influential taxa decreased in that time. This pattern was not consistent in all habitats though; while the average abundance of both Formicidae and Araneae declined in the weed-infested habitat between years, those taxa increased in average abundance in both the rehabilitated and undisturbed habitats. The NMDS plot of arthropod data (Fig. 3) showed points representing data from the weed-infested and rehabilitated habitats grouped by year, but the shift observed between years was in a different direction in each of those habitat types. Within the undisturbed habitat, there is more overlap of the groups from each year of study, suggesting less-distinct differences in community composition between years in this habitat. No consistent pattern was seen across all habitats. Differences in community composition were more distinct in the weed-infested and rehabilitated habitats, suggesting less stability in these habitats than in the undisturbed habitat. That the shift was not consistent in the weed-infested and rehabilitated habitats suggests that the factors influencing the changes in community composition operated differently in these habitats. This finding supports the idea that rehabilitation efforts impacted the successional trajectory of the terrestrial-arthropod community.
Vegetation Community Composition

Analysis of aerial-cover data for vegetation confirmed that differences in vegetation community composition existed between all 3 habitats studied. Vegetation in the rehabilitated habitat differed from that in the weedinfested habitat but did not mimic an undisturbed condition. In contrast, other studies observed restored vegetation similar either to undisturbed or disturbed vegetation (Longcore 2003). Differences in vegetation between the rehabilitated habitat and the other 2 habitats in this study are attributable to B. tectorum and largely to species included in the seed mix used to rehabilitate the area (A. cristatum and E. nauseosa). The inclusion in the seed mix of species not native to the area or native but not occurring in adjacent, undisturbed areas suggests that strict restoration was not the goal of rehabilitation in this case. Rather, goals were probably to limit weed invasion, provide perennial resistance to soil erosion, and restore ecosystem functionality, all by introducing species that are more easily established and that may in some ways be ecologically equivalent to native species in adjacent, undisturbed habitats. That species intentionally introduced by the rehabilitation practices were still present is an indication that rehabilitation was effective.

The inclusion and persistence of the nonnative A. cristatum in rehabilitation efforts was consistent with other rehabilitation projects (Rogler and Lorenz 1983, Assay et al. 2001, Waldron et al. 2005). As seen in other seeding projects including A. cristatum, the rehabilitated habitat had lower cover of annual weeds (especially B. tectorum) than either the weedinfested or undisturbed habitats (Waldron et al. 2005) and can thus be seen as an improvement in some respects over both of the other habitats studied. Though the vegetation composition of the undisturbed habitat was more similar to vegetation in the weed-infested habitat than it was to vegetation in the rehabilitated habitat, some components of the vegetation community and related variables (e.g., diversity, total shrub cover) in the rehabilitated habitat more closely resembled conditions observed in the undisturbed habitat than those observed in the weed-infested habitat. More shared species were observed between the undisturbed and rehabilitated habitats than between the undisturbed and weed-infested 
habitats. Thus, while the vegetation composition of the rehabilitated habitat differed from that of an undisturbed condition, rehabilitation resulted in an improvement over a weedinfested condition and a shift of some components toward an undisturbed condition.

\section{Ground Cover}

Analysis of ground-cover data demonstrated that while ground-cover characteristics of the weed-infested habitat differed significantly from what was observed in both the rehabilitated and undisturbed habitats, the undisturbed and rehabilitated habitats displayed no difference in ground-cover characteristics. Thus, groundcover data suggest that the rehabilitation efforts in this instance were effective in restoring some ecological components to conditions like those observed in an undisturbed system.

\section{Relating Arthropod and Environmental Data}

Evidence of a relationship between vegetation and arthropod communities was observed; however, the differences between the arthropod communities in the 3 habitats did not strictly follow the same pattern as the differences between vegetation communities (compare Figs. 3 and 4). The arthropod community in the rehabilitated habitat was more similar to the arthropod community in the weedinfested habitat than the arthropod community in the undisturbed habitat was. Vegetation in the undisturbed habitat was more similar to vegetation in the weed-infested habitat than the vegetation in the rehabilitated habitat was. Evidence of a loose relationship between plants and arthropods was also observed by Symstad et al. (2000), who reported a relationship between richness of arthropod species and richness of plant functional groups for only a few orders of arthropods. Others have also observed that dominant vegetation alone failed to fully explain patterns demonstrated by arthropod communities (Ellis et al. 2000, Meyer and Whiles 2008). The terrestrial-arthropod community in this case appears to be related to, but not completely tied to, plant-species composition. Rehabilitation in the current study apparently did restore some component of ecosystem functionality, as the rehabilitated habitat is now capable of supporting an arthropod community different from the community observed in the weed-infested habitat and more similar to the terrestrial-arthropod community in an undisturbed habitat. These findings suggest that though complete restoration of all components of the ecosystem was not observed, the plant species used in rehabilitating the area were in some ways ecological equivalents of the native vegetation.

The relationship described between the terrestrial-arthropod community and the vegetation and ground-cover data does not necessarily imply causation. That is, the vegetation or ground-cover variables do not necessarily drive the terrestrial-arthropod community or vice versa. Because these variables are related, however, simultaneous manipulation of both vegetation and terrestrial arthropods is likely possible, and rehabilitation efforts designed to influence one component may impact the other as well.

\section{Conclusion}

Restoration of communities including populations of both plants and animals is often attempted through vegetation manipulation alone. The assumption behind this type of management is that if a plant community approximating an undisturbed or predisturbance condition can be provided, other characteristics of suitable habitat will develop and populations of taxa occupying higher trophic levels will recolonize the area, thus resulting in eventual restoration of the entire system (Brady et al. 2002, Longcore 2003, Gratton and Denno 2005). Longcore (2003), however, observed a disconnect between a restored plant community and the arthropod community it supported and cited similar results from other studies. In these studies, differences remained apparent between arthropod communities in revegetated sites and those in undisturbed sites.

This study provides evidence of a relationship between vegetation and arthropod communities but does not completely support the idea that vegetation composition alone is responsible for eventual restoration of all components of an ecosystem. That the terrestrialarthropod community in the rehabilitated habitat showed characteristics intermediate to the communities observed in the undisturbed and weed-infested habitats, even though the vegetation did not follow that pattern, suggests that rehabilitation can be beneficial even if complete restoration of a plant community is not practical or possible. Such improvements may 
be important intermediate steps to complete restoration.

Evaluating the effects of disturbance and rehabilitation with arthropod richness data alone was effective in this system but yielded somewhat different results than when arthropod community composition was used as an indicator. Using both richness data and community-composition data gave a more complete picture of conditions in the study site. Both vegetation and arthropod community data were effective indicators demonstrating similarities and differences between the habitats studied. Again, the results of these techniques differed to some extent. Including both vegetation and arthropod community data yielded a more complete understanding of conditions at the study site. Including multiple and diverse variables resulted in a better understanding of the effects of disturbance and rehabilitation and identified specific differences between the habitats studied. Additional study of these discrepancies could lead to improved rehabilitation techniques and thus increased likelihood of ecological restoration in disturbed systems.

\section{ACKNOWLEDGMENTS}

We thank Russell Rader, C. Riley Nelson, and 2 anonymous reviewers for suggestions that improved earlier versions of this manuscript.

\section{Literature Cited}

Anderson, A.N., AND G.P. Sparling. 1997. Ants as indicators of restoration success: relationship with soil microbial biomass in the Australian seasonal tropics. Restoration Ecology 5:109-114.

Assay, K.H., W.H. Horton, K.B. Jensen, and A.J. Palazzo. 2001. Merits of native and introduced Triticeae grasses on semiarid rangelands. Canadian Journal of Plant Science 81:45-52.

Ausden, M., And M. Drake. 2006. Invertebrates. Pages 214-249 in W.J. Sutherland, editor, Ecological census techniques: a handbook. Cambridge University Press, Cambridge, United Kingdom.

BAKKER, J.D., AND S.D. WILSON. 2004. Using ecological restoration to constrain biological invasion. Journal of Applied Ecology 41:1058-1064.

Bess, E.C., R.R. Parmenter, S. Mccoy, and M.C. Molles, JR. 2002. Responses of a riparian forest-floor arthropod community to wildfire in the Middle Rio Grande Valley, New Mexico. Environmental Entomology 31: $774-784$.

Beyers, J.L. 2004. Postfire seeding for erosion control: effectiveness and impacts on native plant communities. Conservation Biology 18:947-956.

BisevaC, L., AND J.D. Majer. 1999. Comparative study of ant communities of rehabilitated mineral sand mines and heathland, western Australia. Restoration Ecology 7:117-126.

Block, W.M., A.B. Franklin, J.P. Ward, Jr., J.L. Ganey, AND G.C. White. 2001. Design and implementation of monitoring studies to evaluate the success of ecological restoration on wildlife. Restoration Ecology 9:293-303.

Brady, V.J., B.J. Cardinale, J.P. Gathman, and T.M. BurTON. 2002. Does facilitation of faunal recruitment benefit ecosystem restoration? An experimental study of invertebrate assemblages in wetland mesocosms. Restoration Ecology 10:617-626.

BRenM, G. 1999. Diversity and community structure of geometrid moths of disturbed habitat in a montane area in the Ecuadorian Andes. Journal of Research on the Lepidoptera 38:1-14.

Burger, J.C., R.A. Redak, E.B. Allen, J.T. Rottenberry, AND M.F. ALLEN. 2003. Restoring arthropod communities in coastal sage scrub. Conservation Biology 17:460-467.

Carignan, V., AND M.A. Villard. 2002. Selecting indicator species to monitor ecological integrity: a review. Environmental Monitoring and Assessment 78:45-61.

Christian, J.M., AND S.D. WILson. 1999. Long-term ecosystem impacts of an introduced grass in the northern Great Plains. Ecology 80:2397-2407.

Clarke, K.R., and R.N. Gorley. 2006. Primer v6: user manual/tutorial. PRIMER-E Ltd., Plymouth, United Kingdom.

Clarke, K.R., and R.M. Warwick. 2001. Change in marine communities: an approach to statistical analysis and interpretation. 2nd edition. PRIMER-E Ltd., Plymouth, United Kingdom.

Ellis, L.M., M.C. Molles, Jr., C.S. Crawford, and R. Heinzelmann. 2000. Surface-active arthropod communities in native and exotic riparian vegetation in the Middle Rio Grande Valley, New Mexico. Southwestern Naturalist 45:456-471.

Gotelli, N.J., AND R.K. Colwell. 2001. Quantifying biodiversity: procedures and pitfalls in the measurement and comparison of species richness. Ecology Letters 4:379-391.

Gotelli, N.J., AND G.L. Entsminger. 2001. EcoSim: null models software for ecology. Version 6.0. Acquired Intelligence, Inc., and Kesey Bear. Available from: http://homepages.together.net/ gentsmin/ecosim.html

Gratton, C., AND R.F. DEnNo. 2005. Restoration of arthropod assemblages in a Spartina salt marsh following removal of the invasive plant Phragmites australis. Restoration Ecology 13:358-372.

Harris, G.A., AND J.P. Dobrowolski. 1986. Population dynamics of seeded species on northeast Washington semiarid sites. Journal of Range Management 39:46-51.

Herrick, J.E., G.E. Schuman, And A. Rango. 2006. Monitoring ecological processes for restoration projects. Journal for Nature Conservation 14:161-171.

KaRR, J.R., AND D.N. KimberLing. 2003. A terrestrial arthropod index of biological integrity for shrubsteppe landscapes. Northwest Science 77:202-213.

KNaPP, P.A. 1996. Cheatgrass (Bromus tectorum L.) dominance in the Great Basin desert-history, persistence, and influences to human activities. Global Environmental Change - Human and Policy Dimensions 6:37-52.

Kremen, C., R.K. Colwell, T.L. Erwin, D.D. Murphy, R.F. Noss, and M.A. SAnjayan. 1993. Terrestrial 
arthropod assemblages: their use in conservation planning. Conservation Biology 7:796-808.

Lomov, B., D.A. Keith, D.R. BRitTon, and D.F. Hochuli. 2006. Are butterflies and moths useful indicators for restoration monitoring? A pilot study in Sydney's Cumberland Plain Woodland. Ecological Management and Restoration 7:204-210.

LONGCORE, T. 2003. Terrestrial arthropods as indicators of ecological restoration success in coastal sage scrub (California, U.S.A.). Restoration Ecology 11:397-409.

Mattoni, R., T. LONGCORE, and V. NOVOtny. 2000. Arthropod monitoring for fine-scale habitat analysis: a case study of the El Segundo sand dunes. Environmental Management 25:445-452.

McIntyre, N.E., J. Rango, W.F. Fagon, and S.H. Faeth. 2001. Ground arthropod community structure in a heterogeneous urban environment. Landscape and Urban Planning 52:257-274

Melgoza, G., AND R.S. NowaK. 1991. Competition between Bromus tectorum L. and 2 native species after fireimplications from observations and measurements of root distribution. Journal of Range Management 44: $27-33$.

Meyer, C.K., AND M.R. WhiLEs. 2008. Macroinvertebrate communities in restored and natural Platte River slough wetlands. Journal of the North American Benthological Society 27:626-639.

Moretti, M., P. Duelli, And M.K. Obrist. 2006. Biodiversity and resilience of arthropod communities after fire disturbance in temperate forests. Oecologia 149:312-327.

Nichols, O.G., AND F.M. Nichols. 2003. Long-term trends in faunal recolonization after bauxite mining in the Jarrah forest of Southwestern Australia. Restoration Ecology 11:261-272.

Ogle, S.M., W.A. Reiners, and K.G. Gerow. 2003. Impacts of exotic annual brome grasses (Bromus spp.) on ecosystem properties of northern mixed grass prairie. American Midland Naturalist 149:46-58.

Parmenter, R.R., AND J.A. MacMahon. 1987. Early successional patterns of arthropod recolonization on reclaimed strip mines in southwestern Wyoming: the ground-dwelling beetle fauna (Coleoptera). Environmental Entomology 16:168-177.

. 1990. Faunal community development on disturbed lands: an indicator of reclamation success. Pages 73-89 in J.C. Chambers and G.L. Wade, editors, Evaluating reclamation success: the ecological consideration. USDA Forest Service, Northeastern Forest Station, Radnor, PA.

Parmenter, R.R., J.A. MacMahon, and C.A.B. Gilbert. 1991. Early successional patterns of arthropod recolonization on reclaimed Wyoming strip mines: the grasshoppers (Orthoptera: Acrididae) and allied faunas (Orthoptera: Gryllacrididae, Tettigoniidae). Environmental Entomology 20:135-142.

Pellant, M. 1990. The cheatgrass-wildfire cycle-are there any solutions? Pages 11-18 in ProceedingsSymposium on cheatgrass invasion, shrub die-off, and other aspects of shrub biology and management, Las Vegas, NV. General Technical Report INT-276, USDA Forest Service, Ogden, UT.

Pik, A.J., I. Oliver, and A.J. Beattie. 1999. Taxonomic sufficiency in ecological studies of terrestrial invertebrates. Australian Journal of Ecology 24:555-562.

Roberts, T.C., JR. 1990. Cheatgrass: management implications in the 90's. Pages 19-21 in Proceedings-
Symposium on cheatgrass invasion, shrub die-off, and other aspects of shrub biology and management, Las Vegas, NV. General Technical Report INT-276, USDA Forest Service, Ogden, UT.

Rogler, G.A., And R.J. Lorenz. 1983. Crested wheatgrass-early history in the United States. Journal of Range Management 36:91-93.

Roundy, B.A., N.L. ShaW, and D.T. BoоTh. 1997. Using native seeds on rangelands. Pages $1-8$ in N.L. Shaw and B.A. Roundy, compilers, Proceedings: using seeds of native species on rangelands. General Technical Report INT-GTR-372, USDA Forest Service, Intermountain Research Station, Ogden, UT.

Ruiz-Jaen, M.C., And T.M. Aide. 2005a. Restoration success: how is it being measured? Restoration Ecology 13:569-577.

. 2005b. Vegetation structure, species diversity, and ecosystem processes as measures of restoration success. Forest Ecology and Management 218:159-173.

Schnell, M.R., A.J. Pik, and J.M. Dangerfield. 2003. Ant community succession within eucalypt plantations on used pasture and implications for taxonomic sufficiency in biomonitoring. Austral Ecology 28: $553-565$.

Soll Survey Staff. 2007. Web Soil Survey. Natural Resources Conservation Service, United States Department of Agriculture; [accessed August 2007]. Available from: http://websoilsurvey.nrcs.usda.gov/.

Symstad, A.J., E. Siemann, And J. Haarstad. 2000. An experimental test of the effect of plant functional group diversity on arthropod diversity. Oikos 89: 243-253.

Triplehorn, C.A., AND N.F. Johnson. 2005. Borror and DeLong's introduction to the study of insects. 7th edition. Thomson Brooks/Cole, Belmont, CA.

USDA Forest SERvice. 2004. Forest Service manual 2523: burned area emergency rehabilitation. USDA Forest Service, Washington, DC.

Updike, D.R., E.R. LofT, and F.A. HaLL. 1990. Wildfires on big sagebrush/antelope bitterbrush range in northeastern California: implications for deer. Pages 41-46 in Proceedings-Symposium on cheatgrass invasion, shrub die-off, and other aspects of shrub biology and management, Las Vegas, NV. General Technical Report INT-276, USDA Forest Service, Ogden, UT.

Waldron, B.L., T.A. Monaco, K.B. Jensen, R.D. HarriSon, A.J. Palazzo, and J.D. Kulbeth. 2005. Coexistence of native and introduced perennial grasses following simultaneous seeding. Agronomy Journal 97: 990-996.

Webb, C.E., I. Oliver, And A.J. Pik. 2000. Does coastal foredune stabilization with Amophila arenaria restore plant and arthropod communities in southeastern Australia? Restoration Ecology 8:283-288.

Whisenant, S.G. 1990. Changing fire frequencies on Idaho's Snake River Plains: ecological and management implications. Pages 4-10 in ProceedingsSymposium on cheatgrass invasion, shrub die-off, and other aspects of shrub biology and management, Las Vegas, NV. General Technical Report INT-276, USDA Forest Service, Ogden, UT.

Received 25 September 2008 Accepted 9 June 2009 